\section{Procreation: How Others Perceive Those Who Cannot or Will Not}

\section{Abstract}

Research indicates childless couples in the United States, a pronatalist society, are stigmatized regardless of why they are childless. In the current study, 152 college students rated a couple who was either voluntarily childless, involuntarily childless, or parents on a variety personality traits, and reported their perceptions of the couple and their relationship satisfaction. A loan approval task was utilized as a subtle measure of discrimination. Although no statistically significant differences between couples existed, the loan rates were in the hypothesized direction. Additionally, the mother was perceived significantly more favorably than the childless wives regardless of why they were childless.

Keywords: Voluntarily childless; Contraceptives; Sexually dysfunctional; Stigmatization; Emotional

Received: April 04, 2017; Accepted: April 18, 2017; Published: April 30, 2017

\section{Michelle R Maegly, Christian M End and Krysten M Knecht}

\author{
Xavier University, Cincinnati, Ohio, USA
}

\section{Corresponding author: Christian M End \\ end@xavier.edu}

Associate Professor, School of Psychology, ML 6511 107D Elet Hall, Xavier University, Cincinnati, Ohio, USA.

Tel: (513) 745-3249

Fax: (513) 745-3327

Citation: Maegly MR, End CM, Knecht KM. Procreation: How Others Perceive Those Who Cannot or Will Not. Acta Psychopathol. 2017, 3:3.

\section{Introduction}

According to the Center for Disease Control, rates of childlessness are on the rise in the United States [1]. Though rates of voluntary and involuntary childlessness have increased, some argue that remaining childless, whether or not by choice, violates societal norms of the past and the present $[2,3]$.

\section{Pronatalism}

Many theorists contend that the U.S. culture is historically and currently pronatalist, which is defined as having attitudes and policies that positively reinforce those who parent children [3,48]. Consequently, couples who choose not to have children or are unable to have children violate societal norms and may thus be stigmatized [7].

\section{Stigma and norm violation}

Goffman [8] argued that when individuals are perceived by others as having violated entrenched social norms, those individuals may become victims of stigmatization. This would include those who violate pronatalist norms by remaining childless [911]. Furthermore, "people who are stigmatized ... are generally devalued in the larger society, and receive disproportionately negative interpersonal and economic outcomes" [11].

\section{The Stigma of Voluntary Childlessness}

Gold and Wilson [12] suggested couples may choose not to have children for reasons such as: A desire to focus on career; lack of resources; desire for freedom; a wish to not add to overpopulation and/or pollution; dislike of children; and not wanting to bring children into an unsafe world. However, society may view these justifications as unacceptable [10].

Results from numerous quantitative studies have indicated that voluntarily childless individuals were perceived more negatively than parents, including being perceived as more socially undesirable, less well adjusted, less likeable, and more psychologically disturbed [13-15]. A qualitative study revealed that others perceive the childless as selfish, lonely in their old age, strange, weird, unstable, irresponsible, rejecting their natural desire to parent, and unfulfilled; attitudes that are likely easily observed by the voluntarily childless individuals.

Empirical evidence lends support to the claims that voluntarily childless couples are aware of these negative stereotypes. Somers [7] reported that childfree participants inferred that their relatives and friends perceived their choice to be "voluntarily childless" negatively, whereas parent participants reported that they did not feel that others harbored negative attitudes toward their choice to parent [7]. During in-depth interviews with voluntarily childless individuals, one participant described the social impact of her choice to remain childless as the "last taboo, the last alternative lifestyle" [10]. A second participant also recognized the social pressure to parent and stated, "...in society 
I'd be labeled as a bad person, so normally I say [to peers that] I'm not ready for that responsibility yet," (p: 33). This evidence that those who choose childlessness perceive themselves to be stigmatized may cause one to wonder if those who cannot conceive also perceive themselves to be victims of stigmatization.

\section{The Stigma of Involuntary Childlessness}

An infertile couple is defined as a couple attempting to conceive who engages in at least one year of regular intercourse without success and without prior conception, or the failure of a woman to carry a pregnancy to term [4]. This situation becomes a reality for approximately $10 \%$ of women in their reproductive years [16]. Possible factors contributing to infertility include postponement of childbearing until the late 30 s, sexually transmitted infections, consequences of long-term use of contraceptives, and advanced technology for detecting infertility [16]. Infertility can be a difficult and painful situation, especially for those who reside in a society that is traditionally pronatalist.

Though adequate social support can help a couple cope with the loss of their reproductive ability, it is not always forthcoming or sought. Many couples have reported significant feelings of loneliness, isolation, and a lack of genuine social support from relatives and friends $[17,18]$. Some infertile women never speak to others about their infertility because they assume parents would not understand their plight, and childless couples may avoid attempting to socialize with parents for fear that they would have little in common with similarly aged parents [19].

Involuntarily childless couples may be stigmatized because others cannot visually observe the physical malfunctions that cause infertility. Thus, observers may have attributed all of the aforementioned negative stereotypes associated with voluntarily childlessness to a couple who actually desires offspring but are unable to give birth [6]. In addition to attribution errors, the infertile have also been assumed to be physically dysfunctional [6], sexually dysfunctional [2] or deserving of barrenness according to various religious and cultural perspectives [19], which contributes to involuntarily childless couples experiencing feelings of inadequacy and shame [6].

\section{Understanding Stigmatization}

Regardless of the voluntary or involuntary nature of a couple's childlessness, there is much support for the postulation that childless couples are victims of stigmatization. Stigmatization has been defined as a four component process: labeling differences (e.g. childless), associating those differences with stereotyped traits (e.g. selfish, uncaring, etc.), separation of individuals from the majority population (e.g. lack of social support) and, finally, the loss of status and/or discrimination.

Attribution theory is useful in understanding the underlying processes for why an individual is stigmatized $[20,21]$. The extent to which one is stigmatized may be determined by the level of controllability attributed to her or his negative characteristics and behaviors. When a person is perceived to be in control of, and thus responsible for her/his norm-violating behavior, negative perceptions are formed of the individual and the individual may be perceived as "deserving" stigmatization. For example, if childlessness is perceived as a norm-violating state, and within the childless individual's control, negative attributes associated with childlessness are applied to the individual resulting in stigmatization. On the other hand, if childlessness is considered an undesirable state but is not considered under the childless person's control nor is the person perceived as responsible for her/his childlessness, stigmatization may be avoided. Research has provided empirical support for the aforementioned processes by studying how participants perceive individuals with various physical and mental-behavioral disabilities when the perceived levels of controllability vary $[9,21]$.

Based on the results that those who are not perceived to be in control of or responsible for their condition are less likely to be perceived negatively, one might assume that individuals who are childless due to a physical condition may be more worthy of support or pity because they are not responsible for their condition; subsequently, voluntarily childless individuals are more responsible for their norm violating behavior and thus perceived as more deserving of stigma.

\section{Belief in a Just World and Stigmatization}

Although the impact of others' attributions on stigmatization has been empirically established, it is also possible that individual differences between observers, such as belief in a just world (BJW), may also mediate whether or not a target is stigmatized. According to the Just World Hypothesis [22] individuals are motivated to believe that the world is just and fair; good things happen to good people, and bad things only happen when a person deserves it. Perceivers with a high need to believe in a just world may derogate a victim by reasoning that the person deserved the negative outcome, thus preserving their belief that the world is still just [22]. As evidenced by a 2005 meta-analysis of BJW research since 1980, the most frequent type of BJW research has been the measurement of an individual's belief in a just world to help understand reactions to victims, including victim derogation [23], often with high BJW being associated with fewer acceptances of innocent victims than low BJW.

The current study attempts to measure the extent to which voluntarily and involuntarily childless couples will be victims of stigmatization compared to parents. Additionally, the extent to which the two childless couples are stigmatized will be compared. Consistent with previous literature $[7,10,14,17]$, it is predicted that voluntarily and involuntarily childless couples will be stigmatized when compared to parents. Based upon research regarding the controllability of a condition affecting stigmatization, with controllable conditions garnering more stigma $[9,21]$, the voluntarily childless couple will be stigmatized to a significantly greater extent than the involuntarily childless couple. Finally, the degree to which participants believe in a just world will be measured to determine if a greater belief in a just world is positively correlated to the stigmatization of innocent victims, i.e. the involuntarily childless couple. 


\section{Method}

This study was approved by the Xavier University Institutional Review Board.

\section{Participants}

Of the 192 undergraduate students enrolled in psychology courses that were recruited, 152 participants ( 54 men, 94 women, and 4 individuals who did not report their gender) successfully completed all of the study's measures as well as the items that functioned as manipulation checks. The mean age of the participants was 20.27 years $(S D=1.75)$. Of the 152 participants, $76.3 \%$ reported that they were of the Christian faith. Data from participants who were parents or who had attempted to have children were excluded $(n=1)$.

\section{Materials}

Loan approval task: All participants were given descriptions of three different couples applying for a debt-consolidation loan (Appendix A). All three descriptions provided similar information: Basic demographic data, relationship history, and occupational information. Two of the three descriptions were "filler" couples, whose descriptions were standardized for all conditions. The remaining experimental couple description included the manipulation of the independent variable of parental status. In the experimental paragraphs the couple was either described as voluntarily childless ("Danielle and Robert chose not to have children"), involuntarily childless ("Danielle and Robert struggled to have children but were unable to conceive"), or as parents ("Danielle and Robert have two children").

\section{Measurement of impressions}

Personality traits: For the current study, LaMastro's [5] 28item list of bipolar adjectives was used to measure impressions of childless couples. Personality characteristics were rated separately for the wife and the husband on a 7-point bipolar scale for each of the 28 items (i.e., warm/cold, sincere/insincere, welladjusted/not well-adjusted). Each personality characteristic pair presented to the participant has an empirically-based positive and negative pole [24]. The scores for all female items were summed (internal consistency $\alpha=0.91$ ) to create a measure of female impressions; all male items were likewise summed (internal consistency $\alpha=0.90$ ) to create a measure of male impressions. Thus, the minimum score is 28 , the maximum is 196 , and the midpoint is 112 . Higher scores on these measures indicate more positive impressions. It should be noted that participants who failed to respond to more than one of the measure's items were excluded from the sample. If a participant failed to complete a singular item, an averaged score on the measure was calculated and entered in replace of the missing response.

Relationship satisfaction: Lampman and Dowling-Guyer [25] and LaMastro [5] argued that stigmatization may occur in the form of observers' perceptions of lower levels of marital quality amongst childless couples. Thus participants were asked to indicate their level of agreement with a series of seven statements regarding the quality of the couple's relationship $[5,25]$. Sample items included, "Overall, Danielle and Robert will have a good life together," and "Danielle and Robert are likely to stay married for the rest of their lives." Level of agreement was ranked on a 5-point Likert-type scale ranging from strongly disagree (1) to strongly agree (5). The minimum score for this measure is 7 , the maximum is 35 , and the midpoint is 21 . Two items were reverse scored and all items were summed (internal consistency $\alpha=0.73$ ); higher scores indicate more positive perceptions of the couple's relationship.

\section{Belief in a just world}

To determine if an individual's level of belief in a just world (BJW) would impact perceptions of the involuntarily childless, participants completed Lipkus's Belief in a Just World Scale for Others. Participants indicated their agreement with eight statements on a scale ranging from strongly disagree (1) to strongly agree (6). Sample items include, "I feel that people earn the rewards and punishments they get," and "I feel that when people meet with misfortune, they have brought it upon themselves." Items were summed (internal consistency $\alpha=0.83$ ), with higher scores indicating greater BJW.

Procedure: Participants volunteered to take part in a study about impression formation and decision making. They were randomly assigned to one of the three experimental conditions: voluntarily childless $(n=47)$, involuntarily childless $(n=63)$, and parents $(n=42)$, which determined which description of the experimental couple they received. After receiving the loan approval task, participants were informed that three couples had applied for a debt-consolidation loan, but only one loan could be awarded. Participants were then instructed to indicate which of the three couples should receive the loan. They were reminded that their decisions should be based solely on the descriptions provided because the couples' financial situations were equivalent.

After selecting the loan recipients, participants were reminded that real world decisions are often based on limited information. They were told they would complete a series of questionnaires about one of the three couples purportedly designed to gain further information about the factors that impact decisionmaking. In reality, all participants completed the questionnaires about the experimental couple. The questionnaire packet included the personality trait checklist [5] and the relationship satisfaction measure $[5,25]$.

After participants completed the first set of questionnaires, they received a second set of questionnaires which they were told was designed to measure personal characteristics that impact decision-making. These questionnaires included the Belief in a Just World scale for others [26], items designed to determine if the participant attended to and accurately remembered the target couple's parental status (the manipulation check), and the demographics questionnaire.

\section{Results}

\section{Loan approval task}

Because the primary purpose of the study was to determine if differences existed between the experimental couples, a series of 
chi-square tests were used to directly compare the proportion of instances when loans were awarded to the various experimental couples. Although it did not reach the traditional indicator of statistical significance $(p=0.05)$, the difference between the proportion of instances when the voluntarily childless couple received the loan $(31.9 \%)$ and the proportion of instances when the parent received the loan (50\%) was marginally significant, $X^{2}(1, N=89)=2.99, p<0.10$, The proportion of instances when the involuntarily childless couple $(41.3 \%)$ received the loan did not significantly differ from the parents nor the voluntarily childless couple. Although the differences were not statistically significant, Figure 1 shows that the trend was consistent with the study's hypotheses that the voluntarily and involuntarily childless couples would be stigmatized when compared to parents, with the voluntarily childless couple stigmatized to a greater extent than the involuntarily childless couple.

\section{Impressions of couples}

A 3 (parental status: voluntarily childless or involuntarily childless or parents) $\times 2$ (gender of the target: male or female) mixed between-within multivariate analysis of variance was performed to investigate differences in impression scores (sum of the personality traits). The MANOVA revealed no significant main effects, but did indicate a significant Parental status $x$ Gender of the target interaction effect, Wilks' $\Lambda=0.95, F(5,146)=3.83$, $p<0.05$, multivariate $\eta^{2}=0.05$.

The significant Parental status $x$ Gender of the target interaction was further investigated with ANOVAs and post hoc $t$-tests for each of the dependent variables. While the male personality trait scores were unaffected by the couple's parental status, the female personality trait scores differed significant according to parental status, $F(2,149)=3.49, p<0.05$, The pairwise comparisons indicated that impressions of Danielle described as a mother $(M=148.88, S D=21.43)$ were significantly more favorable then the impressions of both descriptions of Danielle as being a

60

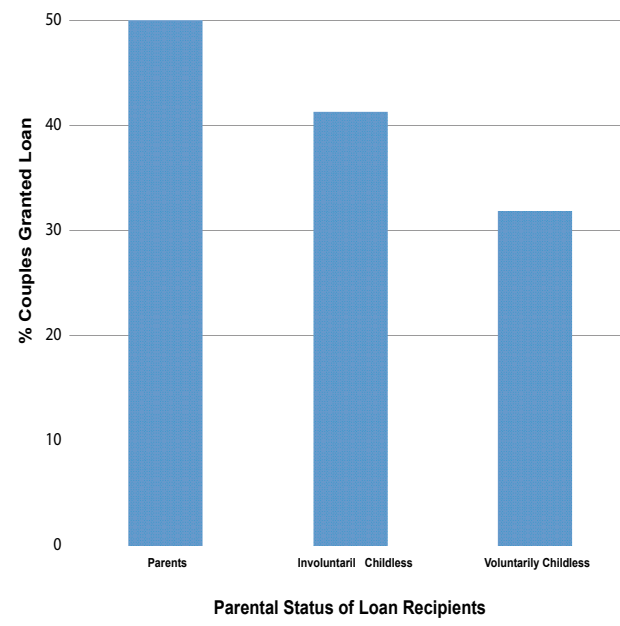

Figure 1 Percentage of couples granted a loan by parental status. voluntarily $(M=140.34, S D=18.91 ; p<0.05)$ and an involuntarily childless $(M=139.33, S D=17.68 ; p<0.05)$ woman. Table 1 for descriptive statistics.

The post hoc $t$-tests also indicated that when the couple was described as being involuntarily childless, the impressions of Danielle was significantly less favorable than the impressions of Robert, $t(62)=2.14, p<0.05$. Although not statistically significant, the direction of this discrepancy was similar when the couple was described as being voluntarily childless. Contrary to this trend, when the couple was described as being parents, Danielle was perceived more favorably than Robert, albeit the difference was not statistically significant.

\section{Relationship satisfaction}

A one-way between-groups ANOVA was performed to determine if parental status affected perceived relationship satisfaction scores. There were no differences between the perceptions of the voluntarily childless', involuntarily childless', and parents' relationship satisfaction scores.

\section{Belief in a just world and stigmatization}

In order to test the hypothesis that there is a positive relationship between belief in a just world and stigmatization of the involuntarily childless couple, a point-biserial correlational analysis was conducted on the scores on the BJW scale and the loan approval decision for the involuntarily childless couple. There was no significant relationship between BJW scores and loan approval for the involuntarily childless couple, $r(63)=-0.12$, $p=0.34$.

To test the hypotheses that higher levels of BJW would have a positive relationship with personality trait checklist ratings of the involuntarily childless couple and the relationship satisfaction, three bivariate correlational analyses were conducted. Results indicated no significant relationship between scores on the measure of BJW and the female personality trait scores, $r(63)=0.07, p=0.59$, the male personality trait scores, $r(63)=-$ $0.09, p=0.49$, and the perceived relationship satisfaction scores, $r(63)=-0.01, p=0.46$.

\section{Discussion}

Observations of authors and results from previous empirical studies $[10,14,15,17]$ have illustrated the tendency of Western culture to stigmatize individuals who do not procreate. The goal of the present study was to determine if this stigmatization continues to occur. Grounded in the previous research, it was hypothesized that both childless couples would be stigmatized, with the greatest level of stigmatization associated with the voluntarily childless couple. In the current study stigmatization was limited to the female target. Specifically, participants perceived the mother significantly more favorably than the involuntary and voluntary childless wives, who were not rated significantly differently by participants. Additionally, the childless women were perceived more negatively compared to their childless male partners; while the mother was viewed more favorably than her mate (the difference was statistically significant only for the involuntarily 
Table 1: Means and standard deviations of impression scores by parental status.

\begin{tabular}{|c|c|c|c|}
\hline & Parents & $\begin{array}{c}\text { Involuntarily } \\
\text { Childless }\end{array}$ & $\begin{array}{c}\text { Voluntarily } \\
\text { Childless }\end{array}$ \\
\cline { 2 - 4 } & $M(S D) n=42$ & $M(S D) n=63$ & $\begin{array}{c}M(S D) \\
n=47\end{array}$ \\
\hline Measure & - & - & - \\
\hline Female & $148.88(21.43)^{\mathrm{a}}$ & $139.33(17.68)^{\mathrm{b}}$ & $140.34(18.91)^{\mathrm{b}}$ \\
\hline Male & $145.41(26.58)$ & $142.50(18.92)$ & $142.37(19.89)$ \\
\hline Relationship & $26.32(3.20)$ & $25.37(3.27)$ & $25.42(3.58)$ \\
\hline
\end{tabular}

Note: Within rows, means with different subscripts differ significantly at $p<0.05$

childless couple). A secondary aim of the study was to determine if the stigmatization of childless couples would manifest as discrimination, the behavioral component of prejudice. Although this study failed to find support for the hypothesis that the stigmatization would manifest in the form of significantly lower loan approval proportions for the childless couples, it should be noted that the loan rates were in the hypothesized direction. Finally, the observer's level of belief in a just world was explored as a possible explanation for stigmatization. There was no significant relationship between the participant's belief in a just world and stigmatization of the involuntarily childless couple.

Our finding that childless females, regardless of the cause of the childlessness, were perceived more negatively than mothers is consistent with previous literature [5]. However, inconsistent with our findings, LaMastro [5] also found fathers to be perceived more positively than childless men; this may suggest that perceptions of females are more closely dependent upon their parental status compared to men. Hird and Abshoff [3] posit that "As women have challenged their supposed physical, intellectual, economic, and social inferiority, sexual reproduction has become an increasingly important signifier by which women are differentiated by men," (p: 347). Post-feminist movement sex-role stereotypes equating healthy, adult, well-adjusted women with a prerequisite of motherhood is evidenced in literature dating back to the 1970 s $[15,17,27]$. In contrast, perhaps fatherhood may not be a prerequisite to be a healthy, adult male [3].

Though our results suggest that the childless women are perceived less positively than mothers, evidence of discrimination toward the couple, operationalized as the couple being less likely to receive a loan, was not statistically supported. Albeit, it should be noted that the percentages of couples receiving loans were in the hypothesized direction. The lack of statistical significance may be due to the consistent perceptions of the male partners regardless of parental status. Participants may have been conflicted by their motivation "to punish" the stigmatized wife who turned her back on the defining role of motherhood, while simultaneously lacking motivation "to punish" the husband who failed to fill a less central requirement of manhood. Thus participants discriminated against the wife when deciding to make the loan, but their failure to blame the husband and in turn the consistency in which they perceived the husband across parental status prevented the differences in loan rates from achieving statistical significance. Future research might investigate the implications of parental status on behavior toward women independent of their mates versus as a couple. Possible scenarios to be explored might include how women of varying parental status might be discriminated against in regards to social occasions (e.g., invites to baby showers, participation in social circles); occupational domains (e.g., hireability, career choice, promotion potential), as well as other life domains.

The subtle manipulation of the independent variable may offer a potential explanation for the statistically non-significant results for the loan task. When the results of the manipulation check were analyzed, it became evident that almost $20 \%$ of the participants did not correctly remember the target couple's parental status $15 \mathrm{~min}$ after reading about the couple. Given the fact that so many participants missed the manipulation, one might conclude that parental status is not information to which college age participants attended; thus parental status may not be considered as important as other characteristics (age, employment, etc.) when making the decision to award the loan. Though it may not have been salient to our sample, evidence indicates that both parents and childless married couples perceive a possible relationship between parental status and perception formation [7].

Alternatively, if parental status is an important variable to consider in decision making, others' perceptions might only be affected when parental status is assumed to be permanent. Historically, interviews of childless individuals revealed that the choice to remain childless has been regarded as being only temporary, with a later choice for parenthood. This could account for why BJW and stigmatization of the infertile couple were unrelated. To the childless participants, the inability to have children may not be readily perceived as a significant, permanent, life-altering disaster. Thus those individuals who have a high need to believe in a just world would not need to derogate the involuntarily childless couples because they are not perceived as "victims." Future research might examine if scientific fertility advancements have rendered the idea of involuntary childless obsolete.

Demographic characteristics of the sample may have attenuated the results, rendering the analysis of discrimination with the loan task statistically insignificant. Voluntarily childless individuals are typically female; primarily Caucasian, educated, and middle class, career focused, and value contribution to society [3], all traits which describe the majority of the sample population. Younger individuals have also perceived the choice to remain childless more liberally than older adults $[15,27]$.

Perhaps the most obvious observer characteristic influencing stigmatization of childlessness is the parental status of the observer. The theory that differences between an individual and a target must be noted by the individual before discrimination can occur [28] might predict that childless participants would be less likely to discriminate against a childless target couple. Future research might benefit from revisiting the use of parents as participants because the tendency to stigmatize the childless 
may be stronger for them than a college age sample. Parents may have a greater tendency to discriminate against the childless due to differences from the childless, which may include a variety of lifestyle differences in addition to different parental statuses. Priorities, values, allocation of physical, emotional and mental energies, social connections, and how leisure time is spent may vary drastically between parents and non-parents. Parents may stigmatize the childless more than college students because the parents have already engaged in the first two stages of the discrimination process, perceiving and labeling differences [28], to a greater degree than the college students. However, selfpresentational motives may affect parents' responses on a more obvious measure of stigmatization such as the personality trait checklist, and thus the loan task used in this study might be more effective at detecting subtle stigmatization and discrimination by parents. Additionally, the use of the loan task may be more relevant to parents than college students, who are probably less likely than parents to have undergone the process of obtaining a loan. Regardless, researchers might consider investigating other observer characteristics to determine if they predict the stigmatization of the childless, such as: age, the size of family of origin, general degree of diversity tolerance, locus of control, level of belief in traditional sex roles, education level, and personal desire for children.

If future research validates the results of the current study across the various measures of stigmatization, then stigmatization of childlessness, especially in regards to women, may not yet be an artifact of the past. More work may need to be done to increase acceptance of varied family sizes and structures. Until then, clinicians may need to recognize childlessness as another facet of diversity that impacts how individuals and couples relate to others and each other, and that childlessness may sometimes place individuals, particularly women, at risk for stigmatization. If future research demonstrates that stigmatization no longer exists, clinicians might work toward assisting childless couples to access support and relationships that the childless couple may have once overlooked due to the assumption that they would be stigmatized $[7,10,18,19]$.

Historically there have been shifts in motivations for and perceptions of parenthood, such as the shift from the economic need for children to increased freedom of choice in parenting. However, social pressure to parent and consequences for not rearing children may influence individuals to feel as though their choices remained limited. The results of this study, if valid, may indicate that a shift in perceptions of childlessness has not yet occurred. If society can achieve greater tolerance of diversity and better understanding of childlessness, potential increases in social acceptance of remaining childless may not only positively impact those who will not parent by choice, but also offer a more tolerant and supportive atmosphere for those who cannot conceive. 


\section{References}

1 Chandra A, Martinez GM, Mosher WD, Abma JC, Jones J (2005) Fertility, family planning and reproductive health of US women: data from the 2002 National survey of family growth. National Center for Health Statistics: Vital Health Statistics 23 25: 1-60

2 Gannon K, Glover L, Abel P (2004) Masculinity, infertility, stigma and media reports. Soc Sci Med 59: 1169-1175.

3 Hird MJ, Abshoff K (2000) Women without children: a contradiction in terms? J Comp Fam Stud 31: 347-366.

4 Gerrity DA (2001) A biopsychosocial theory of infertility. The Family Journal: Counselling and Therapy for Couples and Families 9: 151-158.

5 LaMastro V (2001) Childless by choice? Attributions and attitudes concerning family size. Soc Behav Pers 29: 231-244.

6 Miall CE (1986) The stigma of involuntary childlessness. Soc Probl 33: $268-282$

7 Somers MD (1993) A comparison of voluntarily childfree adults and parents. J Marriage Fam 55: 643-650.

8 Goffman E (1963) Stigma: Notes on the management of spoiled identity. Englewood Cliffs: Prentice-Hall.

9 Corrigan P, Markowitz FE, Watson A, Rowan D, Kubiak MA (2003) An attribution model of public discrimination towards person with mental illness. J Health Soc Behav 44: 162-179.

10 Park K (2002) Stigma management among the voluntarily childless. Sociol Perspect 45: 21-45.

11 Schneider ME, Major B, Luhtanen R, Crocker J (1996) Social stigma and the potential costs of assumptive help. Pers Soc Psychol Bull 22: 201-209.

12 Gold JM, Wilson JS (2002) Legitimizing the child-free family: The role of the family counsellor. The Family J Counseling and Therapy for Couples and Families 10: 70-74.

13 Calhoun LG, Selby JW (1980) Voluntary childlessness, involuntary childlessness, and having children: a study of social perceptions. Fam Relat 29: 181-183.

14 Mueller KA, Yoder JD (1997) Gendered norms for family size, employment and occupation: are there personal costs for violating them? Sex Roles 36: 207-220.
15 Polit DF (1978) Stereotypes relating to family-size status. J Marriage Fam 40: 105-114.

16 Jordan C, Revenson A (1999) Gender differences in coping with infertility: A meta-analysis. J Behav Med 22: 341-358.

17 Veevers J (1972) The violation of fertility mores: Voluntary childlessness as deviant behaviour. In Boydell C, Grindstaff C, Whitehead $P$ (eds.) Deviant behaviour and societal reaction. Toronto: Holt, Rinehart and Winston, pp: 571-92

18 Lalos A, Lalos O, Jacobsson L, Von Schoultz B (1986) Depression, guilt and isolation among infertile women and their partners. $J$ Psychosom Obstet Gynaecol 5: 197-206.

19 Johansson M, Berg M (2005) Women's experiences of childlessness 2 years after the end of in vitro fertilization treatment. Scand J Caring Sci 19: 58-63.

20 Weiner B (1995) Inferences of responsibility and social motivation. In Zanna MP (ed.) Advances in experimental social psychology. San Diego: Academic Press, pp: 1-47.

21 Weiner B, Perry R, Magnusson J (1988) An attributional analysis of reactions to stigmas. J Pers Soc Psychol 55: 738-748.

22 Lerner MJ, Simmons H (1966) Observer's reaction to the "innocent victim": compassion or rejection? J Pers Soc Psychol 4: 203-210.

23 Hafer CL, Begue L (2005) Experimental research on just-world theory: problems, developments and future challenges. Psychol Bull 131: 128-167.

24 Anderson NH (1968) Likableness ratings of 555 personality-trait words. J Pers Soc Psychol 9: 272-279

25 Lampman C, Dowling-Guyer S (1995) Attitudes toward voluntary and involuntary childlessness. Basic Appl Soc Psych 17: 213-222.

26 Lipkus I, Dalbert C, Siegler I (1996) The importance of distinguishing the belief in a just world for self-versus for others: Implications for psychological well-being. Pers Soc Psychol Bull 22: 666-677.

27 Ory MG (1978) The decision to parent or not: Normative and structural components. J Marriage Fam 40: 531-539.

28 Link B, Phelan J (2001) Conceptualizing stigma. Annu Rev Sociol 27: 363-385. 